\title{
Dinosaur finds from China
}

\section{Henry Gee}

THE intricate history of Mesozoic China is just beginning to yield to the persistent hammers of the Dinosaur Project, a joint Sino-Canadian initiative to explore Jurassic and Cretaceous sediments in Asia and North America. The idea that China in Upper Jurassic and Lower Cretaceous times (175-100 million years ago) was isolated from other parts of the world is gaining credence, thanks to some spectacular fossil finds in the remote Junggar Basin in the Xinjiang region of northwestern China over the past three years. Lower Jurassic faunas from China looked much the same as those from other places, according to Chang Mee-Mann, Director of the Institute of Vertebrate Palaeontology and Palaeoanthropology (IVPP) in Beijing, but Dale Russell of the National Museum of Natural History in Ottawa, just back from Xinjiang, reports that Upper Jurassic stegosaurs and sauropods from China are very strange compared with those from North America.

Sticking its neck out - Mamenchisaurus had the longest neck of any living or extinct animal. A neck attributable to this genus, or a close relative, has been discovered recently in northwestern China. (Courtesy of the British Museum (Natural History)).

Another member of the expedition, Don Brinkman of the Tyrrell Museum of Palaeontology in Drumheller, Alberta, notes the presence of an unusual temnospondyl amphibian, indicating that the peculiarities are not confined to dinosaurs. The temnospondyls, large, crocodile-like amphibians, persisted into Upper Jurassic times in China and Australia long after their relatives elsewhere had become extinct. Like Australian marsupials today, the archaic temnospondyls and unusual dinosaurs and fish may be the results of isolation on an island continent (see Andrew Milner's recent News and Views article in Nature 338, 117; 1989).

One of the more unusual sauropod dinosaurs is Mamenchisaurus, with the longest neck of any animal, living or extinct (see figure). A Mamenchisaurus skeleton was one dinosaur in an exhibition of six from the IVPP that drew large crowds at the British Museum (Natural History) last year. The Junggar Basin team were excavating the neck of another specimen, or a close relative, when the political upheaval in Beijing forced the Canadians in the team to leave the country. Team leader Zhao Xijin and his colleagues were left to continue the dig.
Recent events may also jeopardize a return visit to Inner Mongolia in August. A huddle of juvenile ankylosaurs of the genus Pinacosaurus were found there last year, and Chang hints that many more exciting finds await discovery.

The period of China's isolation came to an end in Middle to Upper Cretaceous times, when eastern Asia and western North America were united by a Bering Straits land bridge. Even so, there are still many mysteries to unravel. For example, why were advanced ceratopsians (horned

\section{IMAGE}

\section{UNAVAILABLE FOR COPYRIGHT REASONS} in North America, when only their primitive relatives such as Protoceratops and psittacosaurs are found in Asia? Small theropods are found in both areas, as are hadrosaurs (duck-billed dinosaurs). The regional hadrosaur faunas are very distinctive nonetheless: where China has Shantungsaurus, Canada has Saurolophus. Russell suspects that the answers to some of these questions lie in as yet unknown subtleties of tectonics.

The immense dinosaur diversity in China, first made clear by a British Museum (Natural History) expedition in 1982, is what has impressed researchers most. In Russell's opinion, China was the central heartland that kept a peripheral North America stocked with dinosaurs in the Cretaceous. The sustained joint research effort has forged many strong links between China and Canada which, it is to be hoped, will weather political troubles. Most of us grew up familiar with names such as Tyrannosaurus and Triceratops. Tomorrow's children will presumably be equally conversant with Tuojiangosaurus (a stegosaur) and Tsintaoscaurus (a hadrosaur). Henry Gee is on the editorial staff of Nature. dinosaurs such as Triceratops) so abundant

\section{Swinging high}

ONE proposed space experiment features a satellite with a long cable, by which instruments can be lowered into regions of aerospace too dense for the satellite itself. Daedalus is taking this idea to its extreme, and is wondering what use could be made of a satellite cable that reached right down to the Earth's surface.

His answer is free transport. A cable simply hanging from an orbiting satellite and tearing across the ground at $8 \mathrm{~km} \mathrm{~s}^{-1}$, is not an ideal object to hitch a lift on, even if you could catch hold of it. The same cable as an elastic pendulum is much more hopeful. DREADCO's dynamicists are studying the theory of such an elastic cable, dangling from its satellite with a cable car on the end of it. With a suitable combined swinging and stretching motion, the car should at one extreme of its travel lag behind its satellite and stretch downwards on its elastic cable, touching the Earth at rest relative to the surface. The contracting cable would then lift it off again, and speed the car up to swing ahead of its satellite before bringing it down on another point on Earth. Freight or intrepid travellers who entered the car at the first landfall would be carried up in a big cycloidal arc through space, and deposited safely at the second. The energy for their upward journey would be borrowed from the kinetic energy of the satellite and the potential energy of the stretched cable, and repaid back to the system during their descent. In principle, this elegant mode of travel consumes no energy and is truly free.

In practice there are bound to be losses: elastic hysteresis in the cable, and some air drag on the cable car (though it is moving at its slowest while in the atmosphere). A rocket motor on the satellite, fed by fuel pumped up the cable, should maintain the whole system in orbit; small motors on the cable car might also be needed to steer it towards a designated landing site. The cable is the hardest component to design. A uniform cord, even of the best and most elastic fibre material, would break under the take-off loading. But a tapered cable, each section just thick enough to support the sections beneath, should solve the problem.

How to choose the orbit of the new vehicle? A simple circular equatorial orbit would touch few points of importance; an inclined elliptical one would be better. The resulting global itinerary would be rather bizarre. Travellers might have to wait a day or so before the cable car visited a landing site in their neighbourhood; and they might have to hop wildly round the Earth for several orbits before it came down conveniently near their destination. Even so, it should waste much less time than long-haul flying. And the view would be breathtaking. 